\title{
Este povo também quer viver
}

\author{
Alderon P. da Costa *
}

Folo: Marcia Salgado

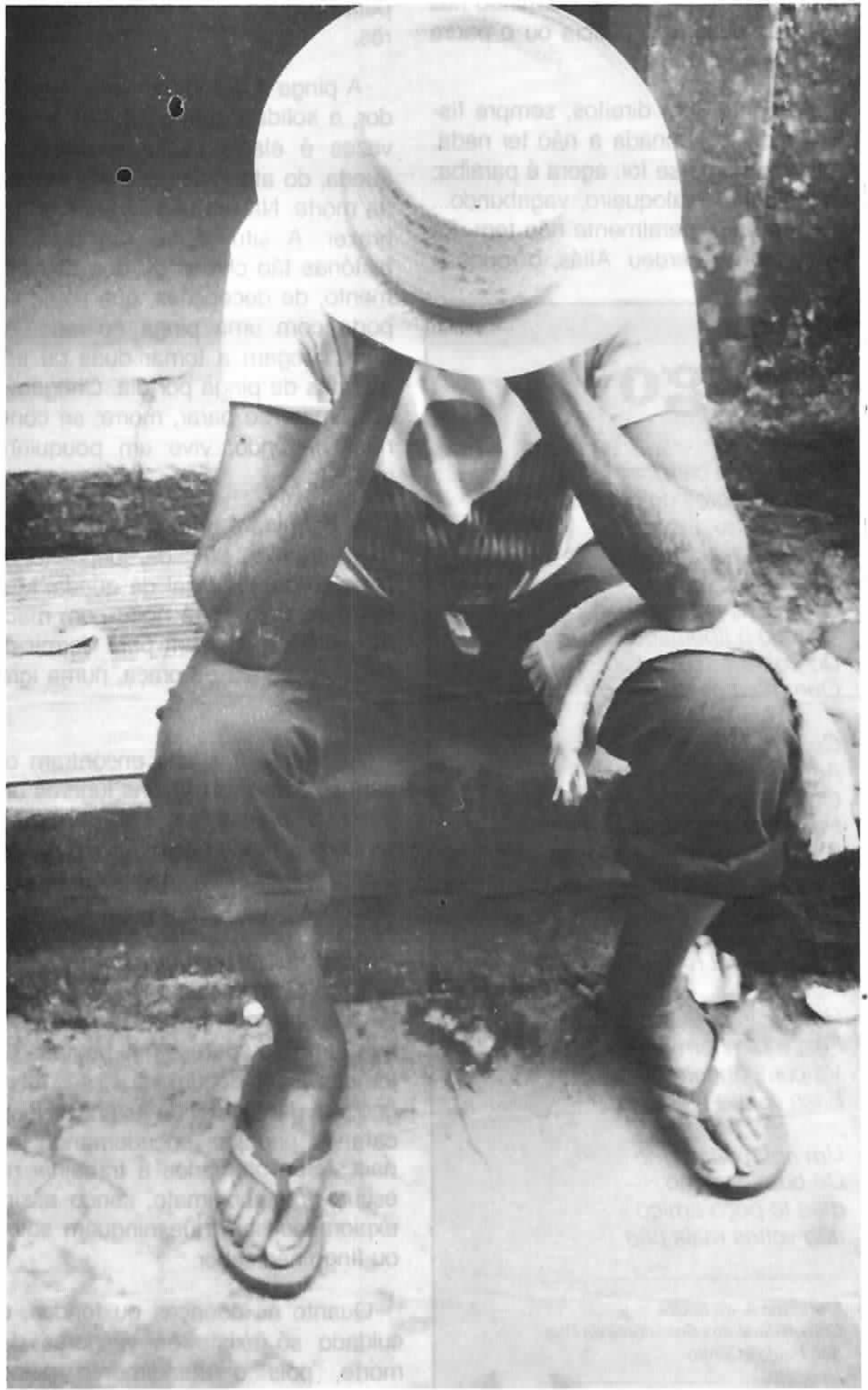

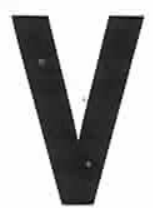

amos falar aqui da situação, dos desafios e das respostas do povo que sofre nas ruas de São Paulo. Vamos enfocar 0 lado da vida, do dia-a-dia, dos questionamentos que brotam da convivência entre nós (agentes) e o povo da rua.

O homem que se encontra na rua ainda nāo é conhecido por nós. As incoerências, a dualidade, a mentira e a verdade, a morte e a vida, são elementos que se misturam constantemente na rua. O homem da rua é um poço de mistério. Não é fácil cativá-lo. O processo de empatia é lento, paciente, pois é feito a partir de dentro. É necessário entrar na rua, conviver com os sofredores em seu "habitat não-natural" (viadutos, praças, albergues, lixo...). É preciso despojar-se do jeito civilizado que aprendemos em casa, na escola, na Igreja. A rua é um outro mundo, nela as leis são diferentes; os comportamentos, os valores, são outros.

Mas antes de continuar a leitura deste relato, vamos trocar de óculos, de posição. Vamos colocar os óculos daqueles que não possuem nada, às vezes nem o próprio corpo. Daqueles que olham a cidade a partir do viaduto, da praça, da rua, do lixo; dos que são rejeitados pela sociedade.

A este povo esmagado, rejeitado, mas que luta para viver, chamamos de Sofredor de Rua Isso porque a situação em que se encontra é muito semelhante a do Povo de Israel descrita pelo profeta Isaias (Is. 49-53) no Canto do Servo Sofredor. "Quem já viu roçado queimado, pois o Servo era um toco pelo sol esturricado. Nāo havia formosura no seu rosto maltratado, tinha a cara tão sofrida de quem foi bem torturado".

Travessia • maio-agosto/89 • 37 
Hoje, a figura do Servo Sofredor está encarnada no favelado, no sem casa, no sem terra, nos menores abandonados, nos negros, nas muIheres, no bóia-fria, no Sofredor de Rua, no indió... Todos eles trazem estampadas no rosto as marcas do sofrimento causado pelas forças da morte. Um dia, porém, descobrem que podem mudar esta situaçāo. Descobrem um apelo para lutar pela vida comunitariamente. E, o Sofredor de Rua coloca-se dentro dessa multidão de empobrecidos que passam a lutar para criar algo novo.

\section{SOFREDOR DA RUA HOMEM DE DOR (Quem é este homem?)}

"Já sonhou. Trabalhou, a sorte desprotegeu.
Desiludiu-se e, mesmo vivo, morreu",

(Elizabete - poetisa da sarjēta)

São homens e mulheres que lutam para sobreviver nos centros das grandes cidades. São eles um retrato vivo da violência urbana. Estão sempre meio escondidos nas sobras da cidade, trabalhando para algum empreiteiro (gato), carregando um fardo de papelẫo na cabeça, encadernando jornais e, às vezes, dormindo nas Igrejas, quando a polícia ou o padre os toleram.

É gente sem direitos, sempre fiscalizada, condenada a não ter nada, até seu nome se foi: agora é paraiba, mineirinho, maloqueiro, vagabundo... Documento, geralmente não tem, foi roubado ou perdeu. Aliás, o roubo é

\section{Adeus amigo}

Vá companheiro

Deus te cubra de graça

Mas faça o favor

De levar sua cachaça

Adeus caro amigo

Os anjos digam amém

Leve sua mudança

E a vassoura também

Despejou os favelados

Com força policial

Cometeu muita violência

Tomou atitude inconstitucional

Como os passes dos idosos

Quis também acabar

Mexeu com os pobres

Querendo mesmo matar

Mexeu com os cobradores de ónibus

Por causa do troco que não há

Se vocé fosse passar na catraca

Tinha também que deixar

Mexeu com os sem terra

Reprimiu os trabalhadores

Mexeu com os ambulantes

Verdadeiros lutadores

Mexeu com o povo da rua

O catador de papeláo

Que dorme pelas calçadas

Por falta de conscientização
Prendeu as carroças

Dos catadores de papelão

Fizeste isto amigo

Por falta de ocupaçâo

Cercou as praças

Tirando a liberdade

Do pobre trabalhador

Que mora nesta cidade

Cercou os viadutos

Aquele último lugar

Onde vivem os sem casa

Por não ter onde ficar

Foi para o exterior

Com o dinheiro suado

Do trabalhador brasileiro

O miserável revoltado

Repreendeu e prendeu

Fez, e também desfez

Vá companheiro amigo

Essa seja a última vez

Um abraço fraterno

De bom coração

mas te peço amigo

não voltes mais não

Francisco A. de Souza

Comunidade dos Sofredores da Rua

Sáo Paulo - Centro uma constante na vida dos Sofredores de Rua Existem até os profissionais em roubar dos Sofredores.

Na rua não se dorme, desmaia-se. $E$ quando isso ocorre, o Sofredor fica de novo sem nada. A violência está sempre presente. É comum aparecerem amigos da rua com a cabeça quebrada, alguma facada, ou até mesmo queimaduras. Estas violências são provocadas pela população, pela polícia e pelos próprios Sofredorès.

A pinga é a companheira contra a dor, a solidão, o frio, a fome. Muitas vezes é ela a causa imediata da queda, do ato violento, e até mesmo da morte. Na rua não se bebe só por prazer. A situação é tão dura, as histórias tão cheias de dor, de sofrimento, de decepçōes, que só se suporta com uma pinga ao lado. Alguns chegam a tomar duas ou três garrafas de pinga por dia. Chegam a um limite: se parar, morre; se continuar bebendo, vive um pouquinho mais.

A dormida é num albergue, viaduto, marquise, calçada, depósito de papelão, ou no local da queda. Muitos nem dormem à noite com medo da violência, deixam para dormir de dia num banco da praça, numa Igreja...

A comida é a que encontram ou ganham. Existem alguns lugares onde, tradicionalmente, a distribuem ou vendem a preço baixo. Outros Sofredores já preferem fazer sua própria comida na rua.

O trabalho também faz parte da vida do Sofredor de Rua Uma grande maioria movimenta uma economia que nảo aparece nas páginas de jornais. Sem documentos, são obrigados a ganhar a vida fazendo bicos, catando papelão, encadernando jornais... São obrigados a trabalhar no escuro, no anonimato, sendo assim explorados sem que ninguém saiba ou finge não saber.

Quanto às doenças ou feridas, o cuidado só existe às vésperas da morte, pois o atendimento pelos hospitais é muito difícil. $E$ quando a 
morte ocorre, é o enterro do indigente.

\section{ANDARILHO, MIGRANTE, EMPOBRECIDO \\ (De onde vem este Povo?)}

As origens sāo muitas: do Norte, Nordeste, Sudeste, enfim, de todos os lugares. São pessoas que buscam sobrevivência, e até uma melhora de vida. Mas caem na rua como derrotados.

$\mathrm{Na}$ sua maioria são pessoas vindas da construção civil. A cada crise econômica percebe-se o aumento de pessoas que nāo encontram outra saída a não ser a rua.

Nos anos de 1980-83, calculavase uma média de 10.000 homens de rua. Em 1987, segundo informaçōes da Secretaria da Promoçāo Social do Estado de São Paulo, a operação inverno registrou 38.419 atendimentos aos Sofredores de Rua. Já em 1988, até 0 mês de julho apenas, haviam sido registrados 61.736 atendimentos.

$\mathrm{Na}$ raiz de tudo, uma causa evidente - o desemprego. Há uma máquina que produz homens de rua. Esta máquina é o sistema econômico que nāo reparte o lucro. O homem 'de rua é fruto dessa injustiça. As causas imediatas (problemas familiares, pessoais e insegurança social) decorrem desse sistema maldito. São sempre os pobres que vão parar na rua. Ainda não conhecemos nenhum rico que tenha desgostado da vida e tenha caído na rua. As frustraçōes pessoais são frutos da fragilidade social, a qual tem suas raízes na situação econômica do país. Este povo, oriundo de vários lugares, é vítima, portanto, de um sistema de morte.

\section{ACREDITAR NA VIDA Nossa Experiência}

"Ai fica claro que o sofrimento, enfrentado com resistência pelo povo, é o caminho por onde Deus vai conduzir a história e trazer para todos a justiça, o direito, a liberdade, a paz, a uniâo, a luz; a liberdade e a paz que - SERVO SOFREDOR é portador" (Carlos Mesters).

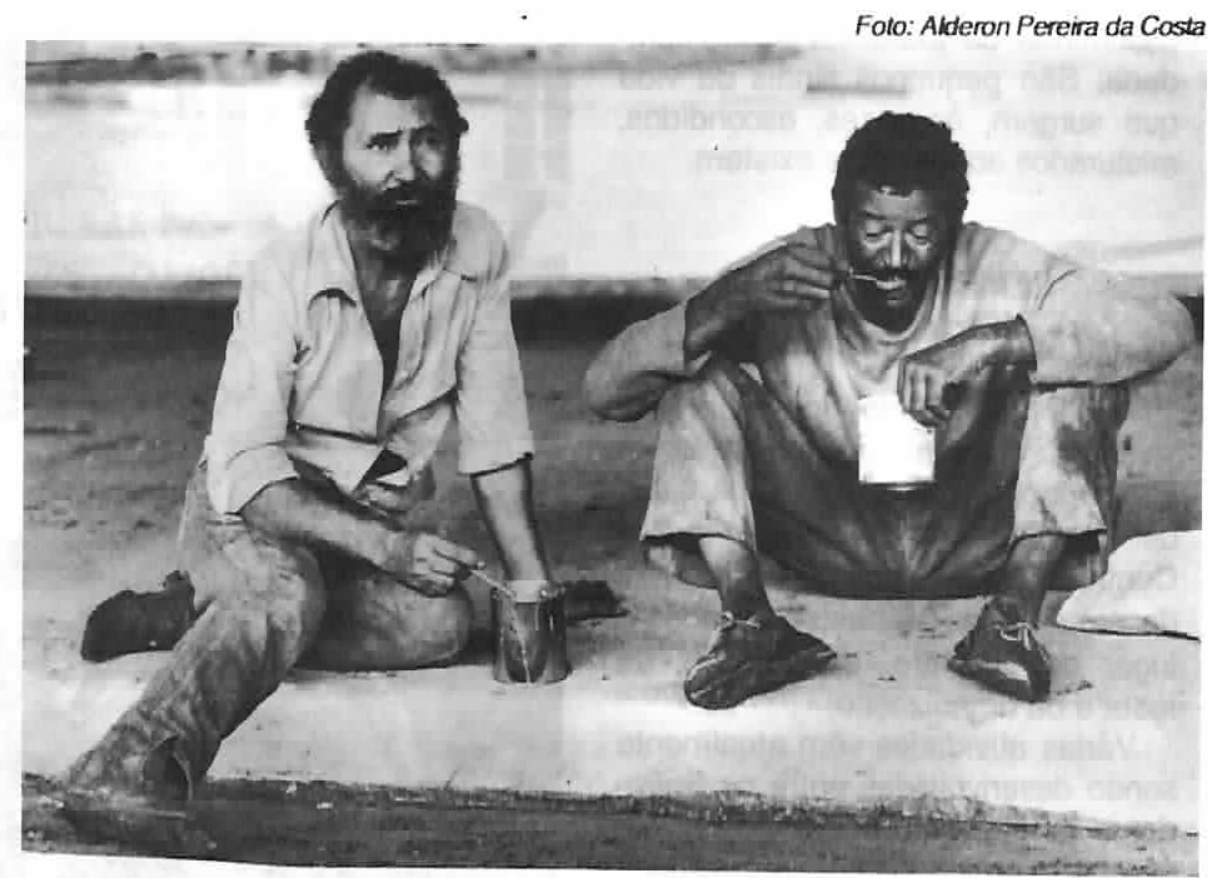

Tudo começou com d. Ignácio Lezama, monge olivetano-beneditino, alguns leigos e um grupo de mulheres que formaram uma fraternidade (Fraternidade das Oblatas de São Bento) para dedicarem-se aos abandonados. Entre estas, vale lembrar, encontrava-se NENUCA que dedicou sua vida até à morte por este povo sofrido. Com a formaçāo desse grupo começou a missão que recebeu o nome de OAF (Organização de Auxílio Fraterno). Em 1979 o cardeal d. Paulo Evaristo Arns lançou um grande desafio para a OAF. "Tragam, quando puderem, o programa de Puebla para o Centro de Sāo Paulo". A equipe de trabalho nāo hesitou; buscou-se, com afinco, novas formas de estar presente na rua. Alguns passaram a dormir nos Albergues; outros, a morar em casas simples, onde o povo tivesse acesso. A convivência com os sofredores de rua era prioridade. Dessa convivência foram surgindo alguns grupos e logo nasceu a necessidade de se ter uma casa para reuniōes, um local para tomar banho, descansar, enfim, um espaço para iniciar alguma organização.

Através da escuta do sofrimento do povo da rua e da leitura da Palavra de Deus, foram sendo abertos novos caminhos. Hoje, existe a COMUNIDADE DOS SOFREDORES DE RUA. Trata-se de uma tentativa de viver a fraternidade, enfrentar os conflitos e buscar novas saidas. E um espaço para o povo da rua, tanto para os que querem sair da rua, como para os que não conseguem ou preferem continuar na rua. A nossa proposta é de, junto com aqueles que querem sair da rua, buscar novas alternativas. Com os que não querem ou năo podem, somos amigos, solidários, irmãos. A nossa experiência mostrou que cada um tem sua história, portanto, as pessoas são diferentes. E cada história, só a ficamos conhecendo a partir de uma longa e profunda convivência. A liberdade maior que eles procuram, nós a respeitamos. No entanto, para participar da comunidade é necessário:

- ser capaz de conviver;

- não usar de violência na comunidade;

- assumir juntos os gastos do Centro Comunitário (ex.: pagando o banho e a roupa que lavam).

A comunidade procura evitar sempre o assistencialismo (onde a pessoa só recebe). Busca sempre a socialização, onde o Sofredor de Rua tem um papel ativo de participação. Ela quer ser suscitadora de consciência e não amortecedora. Não resolvemos o problema de cada pessoa, mas criamos condiçōes e buscamos juntos uma saida. Queremos sim, construir uma comunidade. Muitos que já passaram pela rua estão hoje lutando com a equipe, 
assumindo os trabalhos da comunidade. São pequenos sinais de vida que surgem, às vezes, escondidos, misturados ao lixo, mas existem.

\section{COMUNIDADE SEMENTE DE VIDA \\ (O que existe?)}

Após um período de longa convivência, algumas iniciativas foram despontando. Existe hoje uma Casa de Oração, uma Secretaria e três Centros Comunitários, além, é claro, da própria rua. São estes espaços o lugar do encontro, da reflexāo, da festa e da organização.

Várias atividades vêm atualmente sendo desenvolvidas entre os Sofredores de Rua: sopa comunitária, serenatas, caminhadas, feiras, grupos de reflexão, celebrações, além de grupos organizados em torno dos problemas trabalho e moradia.

Com relação ao trabalho, a organização nasceu junto a alguns catadores de papelão. Antes, cada qual vendia o produto nos depósitos recebendo muito pouco em troca. Mas a partir dos encontros e da criação dos Centros Comunitários, 'o papelāo passou a ser recolhido conjuntamente. O ganho passou a ser maior e a organizaçāo cresceu.

No começo só havia uma carrocinha para o transporte, agora já são nove, todas construídas pelo próprio grupo. Também foi sendo formado um fundo comunitário, sendo que para isso cada membro do grupo destina $10 \%$ do papelão recolhido. Cabe aos membros do grupo ajudar a carregar o caminhão, a limpar o local de trabalho e participar das reuniōes semanais. No momento, está se pensando até mesmo na formação de uma Cooperativa dos Catadores de Papeläo.

\section{ALGUNS DESAFIOS}

Primeiramente, vale dizer que o próprio fato de querer assumir um trabalho junto aos Sofredores de Rua já constitui em si um grande desafio. Trata-se de lidar com pessoas humanas que se encontram numa situação limite. $E$ este desafio torna-se ainda maior quando a filoso40 Travessia maio-agosto/89

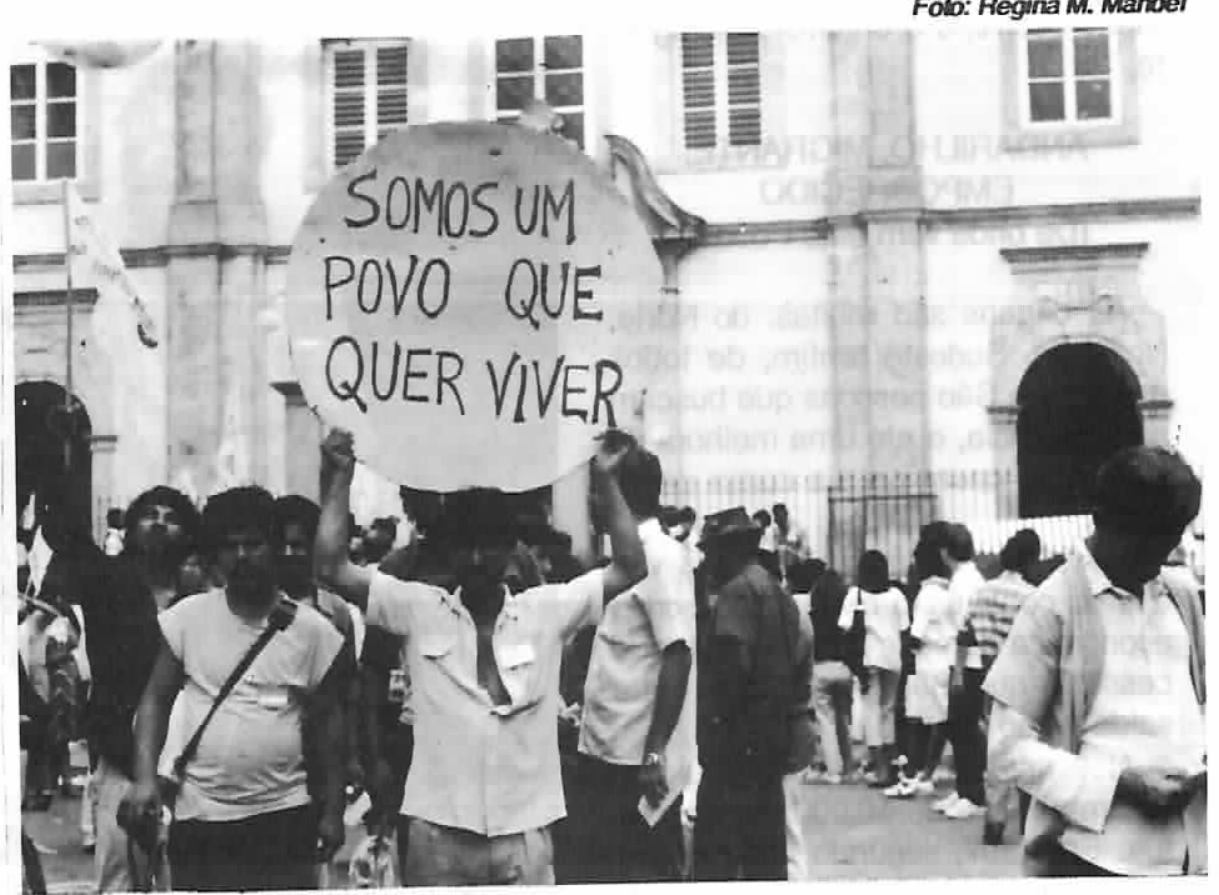

fia que norteia a atuação pauta-se no respeito à liberdade que restou a essa gente e na compreensão da situação em que se encontram.

Nosso ponto de partida para o trabalho, não é o problema que o Sofredor de Rua constitui para a sociedade que se diz civilizada, mas sim - problema que esta sociedade constitui para o Sofredor de Rua. É preciso pois, transformar as estruturas vigentes, transformar a cidade, transformar o homẹm.

É quando surge um novo desafio: é possivel que o homem da rua assuma um peso político? Em São
Paulo são mais de cem mil vivendo nessas condições! Mas, independente da resposta a esta questāo, para os que sonham com uma transformaçāo social, a rua continua sendo um grande desafio. Afinal, numa sociedade que postule ter no ser humano sua preocupação maior, os mais oprimidos têm direito de sonhar com um lugar ao sol. Por ora, um grito ecoa surdo na "Selva de Pedra": este povo também quer viver!

\section{* Agente de Pastoral dos Sofredores de Rua}

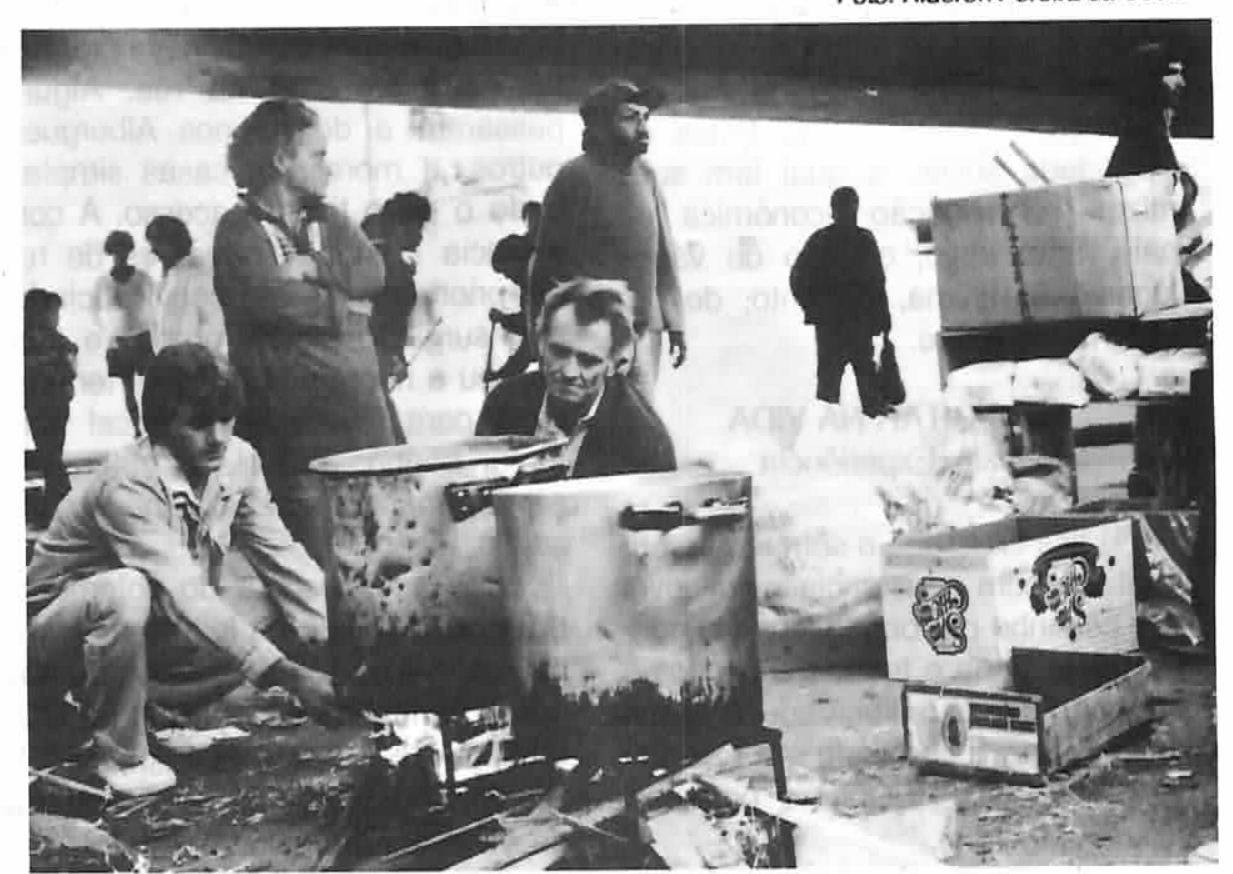

